\title{
RESULTS FROM THE INTRACAROTID AMYTAL PROCEDURE IN PATIENTS WITH UNI OR BITEMPORAL LOBE EPILEPSY AND MESIAL SCLEROSIS
}

\author{
ANA REGINA CANER-CUKIERT, ARTHUR CUKIERT, GARY GRONICH, RAUL MARINO JR
}

\begin{abstract}
SUMMARY - This study discusses the results from the IAP and its lateralizing and prognostic value in patients with temporal lobe epilepsy (TLE) and mesial temporal sclerosis (MTS). Eighteen patients were submitted to the IAP. Fifteen had bitemporal and 3 unitemporal lobe epilepsies. All patients had MTS on MRI and in one there was an unrelated lesion in the contralateral hippocampus. Nine bitemporal patients passed after the injection ipsilateral to the MTS and 4 failed bilaterally. One bitemporal passed bilaterally. Seven of these bitemporal patients passed an injection ipsilateral to MTS and failed on contralateral injection. Two of the unitemporal lobe patients passed the ipsilateral injection and failed the contralateral one. One of the unitemporal lobe patients failed bilaterally the IAP. Overall, $56 \%$ of the group disclosed the pass ipsi- / fail contralateral pattern in the IAP. Eight patients were operated, are seizure free and had no additional memory deficit. Many patients with TLE were found to have the pass ipsi- / fail contralateral pattern in the IAP. This might prove to be of lateralizing and prognostic value in such cases.
\end{abstract}

KEY WORDS: amytal, epilepsy, temporal lobe, surgery.

Resultados do teste intracarotídeo de amital em pacientes com epilepsia uni ou bilateral do lobo temporal e esclerose mesial

RESUMO - Este estudo discute os resultados obtidos no teste de amital sódico (TAS) intracarotídeo e seu valor prognóstica e de lateralização em pacientes com epilepsia do lobo temporal (ELT) e esclerose mesial temporal (EMT). Dezoito pacientes foram submetidos ao TAS. Quinze possuíam epilepsias bitemporais e 3 unitemporais. Todos os pacientes possuíam EMT na RMN e em 1 existia uma calcificação hipocampal contralateral. Nove pacientes bitemporais passaram a injeção ipsilateral à EMT e 4 falharam bilateralmente. Um paciente bitemporal passou bilateralmente. Sctc pacientes bitemporais passaram a injeção ipsilateral à EMT e falharam do outro lado. Dois pacientes unitemporais tiveram este mesmo comportamento. Um paciente unitemporal falhou bilateralmente no TAS. Globalmente, $56 \%$ dos pacientes apresentaram o padrão passa ipsi- / falha contralateral no TAS. Oito pacientes foram operados, estão sem crises e não tiveram déficits adicionais de memória. Muitos pacientes com ELT possuem o padrão passa ipsi- / falha contralateral no TAS. Isto deve representar fator de lateralização e prognóstico relevante.

PALAVRAS-CHAVE: amital, epilepsia, lobo temporal, cirurgia.

The intracarotid amytal procedure (IAP) was first introduced by John Wada and its technique was published in 1949 in Japanese. It allowed, for the first time, the comparison of the functions of each cerebral hemisphere within the same patient and their contributions to speech. The drug was injected in the internal carotid artery and led to transient anesthesia of the perfused regions. It usually flowed through the anterior and middle cerebral systems, but the posterior cerebral artery is also

Divison of Neurosurgery, Department of Neurology, Faculty of Medicine. University of Sāo Paulo. Aceite: 24-abril-1995.

Dr. Arthur Cukiert - Rua Nova York 744 apto 131 - 04560-001 São Paulo SP - Brasil. 
frequently perfused. In 1960, Wada and Rasmussen ${ }^{12}$ published on the effects of intracarotid sodium amytal in animals. Different dosages and concentrations were tested. The authors were thus able to determine the optimal dosage and concentration of the drug suitable for use in humans. They did observe brain lesions in these animals' brains after the use of sodium amytal in a concentration higher then $20 \%$, a concentration much higher than the one currently used in humans (10\%).

In 1964, Branch et al. ${ }^{1}$ showed the results of the IAP in 123 patients in relation to speech lateralization. This was determined by the presence (or absence) of speech difficulties after unilateral injections. They conclude that the IAP would be a good method for speech lateralization and were able to do that in $98 \%$ of the cases. These results were confirmed in several ways: intraoperative mapping of speech areas in dominant hemisphere surgical procedures, absence of speech areas in the intraoperative mapping in non-dominant hemisphere surgical procedures, speech deficits after dominant hemisphere surgery and absence of them after extensive removal of the perisylvian regions in the non-dominant hemisphere.

Angiography was later used to further understand the individual vascular anatomy of these patients. These data were also used to better understand the extention of the anesthetized regions and the atypical results found in some instances.

The IAP began to be used as a predictor of potential memory deficits in patients with temporal lobe epilepsy who were candidates for resective surgery ${ }^{6}$. The bad results obtained while treating 3 patients were the main drive for this development: patient $\mathrm{HM}^{11}$ developed severe amnesia after removal of both temporal lobes (including amygdala and hippocampi); a second patient developed severe memory deficits after unilateral temporal removal while a post-mortem study disclosed a hippocampal lesion at the non-operated side ${ }^{7}$ and a third case in whom a severe memory deficit developed after removal of the mesial temporal lobe structures some years after a neocorticectomy alone was performed ${ }^{\sharp}$. These results suggested an important role of the mesial temporal lobe structures in memory and that bilateral mesial temporal lobe lesions would always originate severe memory deficits. The integrity of the contralateral mesial structures could thus be tested if memory were tested during the IAP. Under these circumstances, the IAP would act as a simulation of the surgical procedure in relation to memory. Additionally, the IAP would suggest that surgery should be restricted to the neocortex in patients with a severe memory deficit following an injection ipsilateral to the focus. On the other hand, the IAP could maximize the surgical resection when memory deficits did not occur and when it confirms the non-dominant nature of an hemisphere when potencially languagerelated areas were to be removed.

The determination of the dominant hemisphere by means of the IAP has also allowed the study of the relatioship between the cerebral and hand dominance in man, particularly in left-handed and ambidextruous patients ${ }^{1}$. A left hemisphere lesion in the early years of life increased the probability of an atypical speech organization. Ninety-six percent of the non-lesionated right-handed patients disclosed a left hemisphere dominance; in 4\%, the right hemisphere was dominant. Within the lefthanded group, $70 \%$ had a left dominant hemisphere, $15 \%$ a right dominant hemisphere and in $15 \%$ there was a bilateral representation of speech. In right handed patients with early lesions to the left hemisphere, a higher percentage of right cerebral dominance was noted (10\%). This was also true for left-handed patients: $67 \%$ of left hemisphere dominance, $22 \%$ of right hemisphere dominance and $11 \%$ of bilateral representation. It should be mentioned that different groups have reported different percentages regarding this issue.

The frequency of patients with bilateral speech representation has increased over the years, even among right-handed individuals ${ }^{13}$. This is most probably due to the more accurate study of subtle speech disturbances after amytal injections ${ }^{5}$. The qualitative study of the language organization process in patients with bilateral specch representation suggested an asymmetric role for each hemisphere. Fifty percent of those patients would show expressive speech deficits in one hemisphere 
and receptive speech deficits in the other ${ }^{5}$. The IAP allows the study of the role of each hemisphere in these patients. The fact that a major part of the population is right handed and with a left hemisphere dominance for speech does not necessarily means that hand and speech dominance are strictly congruent.

The intracarotid injection of sodium amytal causes a transient ipsilateral loss of hemispheric function. There is contralateral hemiplegia immediatly after the injection. If the dominant hemisphere is injected, transient aphasia appears. If the posterior cerebral artery is also perfused, hemianopsia is also noted. Variable memory deficits can occur according to the eventual temporal lobe pathology. Hemiplegia lasts from 4 to 7 minutes. Hemianopsia usually disappears before the motor strenght has come back to normal. Speech disturbances are more severe during the first minutes after injection but dysphasic errors often persist for more than 10 minutes before total normalization of language. Only anterograde memory is affected during the IAP.

The determination of the cerebral dominance is extremely important when surgical procedures are planned in potentially speech-related areas (such as in epilepsy surgery and brain tumors). Refractory complex partial seizures frequently originate from mesio-temporal structures. Contralateral hippocampal integrity should be assessed if an hippocampal removal is planned. The IAP is also indicated in patients with bitemporal epilepsy as determined by imaging (mainly MRI) or EEG. In such instances, contralateral memory assessment after ipsilateral injection is the main concern.

The IAP has been performed in patients of all ages. In some centers, especial stimuli are used for children. Nevertheless, the most important issue is to guarantee that the patient will cooperate with the examiner and not the patient age itself ${ }^{4}$.

1 There is some disagreement on the indications of the IAP2. In some centers, it is part of the basic neuropsychological examination of all patients. On the other hand, it is clear that the use of this invasive methodology is now restricted only as a pre-operative tool in the above mentioned more selected population in the majority of the centers.

This study compares the results obtained during the IAP with the structural abnormalities found in these patients' MRI, mainly mesial temporal sclerosis (MTS).

\section{METHODS}

The IAP was carricd out by a team consisting of a neuroradiologist, clinical neurophysiologist, neuropsychologist, anesthetist, ncurologist and photographer. A percutaneous transfemural catheterization of the internal carotid was peformed. The procedure was monitored by means of EEG and film recording. This allows a precise analysis of the results.

Basal testing consisted of the familiarization of the patient with the IAP environment and served as a way of comparison with the results obtained during injections regarding speech (naming, sequential speech, verbal comprehension) and memory (simple figures, objects, sentences, digits).

Both sides were tested in the same day with an one-hour interval. The most commonly used dosage is $150 \mathrm{mg}$ and a concentration of $10 \%$. Dosage was diminished $(100 \mathrm{mg})$ for use in children.

After the injection, language evaluation consisted of verbal comprehension, reading, naming and sequential speech testing. Memory evaluation consisted of the presentation of new objects (3), figures (2), phrase (1), word for reading (1), sound (1) and object for estereognosia (1). Retrograde memory was also tested. Muscular strenght was monitored by a ncurologist within one-minute intervals and visual analysis of the EEG abnormalities was carried out. The above mentioned parameters were used to determine the period of brain innactivation by the drug. The post-injection testing consisted of the recognition of the items shown before and during the injection, either spontaneously or under a multiple choice paradigm.

Exclusive hemispheric dominance occurred in patients who had aphasia following only one of the injections. Patients with bilateral speech representation comprised a more heterogeneous group: major speech 
disturbances may be found at one injection and minor deficits could occur at the other; severe deficits may be seen after both injections and minor or no deficits could be observed after both injections.

Memory deficits were said to occur if the patient was unable to recouver at least $80 \%$ of the stimuli presented during the action of the drug (Milner's criteria) ${ }^{2}$. It should be emphasized that the stimuli were extremely simple and the purpose of the IAP was to screen for potential post-operative massive memory impairment and not to study the memory processing itself. This is most probably a very strict criteria and false failures may actually be seen. On the other hand, since the surgical approach is modified after failing the IAP, it would be difficult to assess these potentially false failure patients.

Eighteen epileptic patients were submitted to the IAP as part of the pre-surgical evaluation of refractory epilepsy. Fifteen of these patients had bitemporal epilepsy and 3 unitemporal epilepsy. Patients 6 and 14 were considered bitemporal epileptics. Patient 6 had bitemporal structural lesions and a strong right side EEG predominance ( $>90 \%$ ). Patient 14 had right MTS and an exclusive left EEG focus. All of the bitemporal patients had an unilateral MTS and in one of them a contralateral hippocampal lesion was also seen on MRI. All of the unitemporal lobe patients presented MTS on MRI. None of the patients had been submitted to a previous neurosurgical procedure.

\section{RESULTS}

A clinical summary of the subjects submitted to the IAP for memory evaluation, and the results obtained are presented in Table 1 . In 2 patients the IAP was performed unilaterally due to bilateral filling of the middle cerebral artery, as determined by angiography.

Fourteen of the 16 right-handed patients showed left hemisphere language representation. Two of them had language represented in the right hemisphere. No left-handed patients presented right hemisphere language representation, as shown in Table 2.

Table 1. Manual dominance, EEG, MRI and results of 18 patients submitted to the IAP for memory testing.

\begin{tabular}{ccccccc}
\hline Case & $\begin{array}{c}\text { Manual } \\
\text { dominance }\end{array}$ & $\begin{array}{c}\text { Side of major } \\
\text { EEG } \\
\text { abnormality }\end{array}$ & MRI & $\begin{array}{c}\text { Memory ipsi } \\
\text { injection }\end{array}$ & $\begin{array}{c}\text { Memory } \\
\text { contra } \\
\text { injection }\end{array}$ & $\begin{array}{c}\text { Language } \\
\text { representation }\end{array}$ \\
\hline 1 & R & Bitemp & MTS-R & P & F & E \\
2 & R & Bitemp & MTS-R & P & P & E \\
3 & R & R & MTS-R & P & F & E \\
4 & R & L & MTS-L & P & F & E \\
5 & R & Bitemp & MTS-R & P & $*$ & E \\
6 & L & R & MTS-R/CALC-L & F & $*$ & E \\
7 & R & Bitemp & MTS-L & P & F & D \\
8 & R & Bitemp & MTS-L & P & F & E \\
9 & R & Bitemp & MTS-R & P & F & E \\
10 & R & Bitemp & MTS-L & F & F & E \\
11 & R & Bitemp & MTS-R & F & F & E \\
12 & R & R & MTS-R & F & F & D \\
13 & R & Bitemp & MTS-R & F & F & E \\
14 & R & L & MTS-R & F & P & E \\
15 & R & Bitemp & MTS-L & F & F & E \\
16 & R & Bitemp & MTS-R & P & F & E \\
17 & L & Bitemp & MTS-R & P & F & E \\
18 & R & Bitemp & MTS-L & P & F & E \\
\hline
\end{tabular}

R, right; L, left; Bitemp, bitemporal; MTS, mesial temporal sclerosis; calcif, calcification; P, passed; F, failed; *, unilateral testing. 
Table 2. Language representation as determined by the IAP in 18 patients, according to manual dominance.

\begin{tabular}{ccccc}
\hline $\begin{array}{c}\text { Manual } \\
\text { dominance }\end{array}$ & Left & Bilateral & Right & Total \\
\hline Right & 14 & - & 2 & 16 \\
Left & 0 & - & 2 & 2 \\
Ambidextrous & - & - & - & - \\
Total & 14 & - & 4 & 18 \\
\hline
\end{tabular}

L, left; R, right.

Table 4. Memory results according to MTS side in 16 patients submitted to bilateral injections in the JAP.

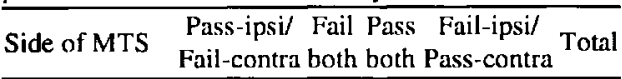

\begin{tabular}{lccccc}
\hline Dominant & 3 & 3 & - & - & 6 \\
Non-dominant & 6 & 2 & 1 & 1 & 10 \\
Total & 9 & 5 & 1 & 1 & 16 \\
\hline
\end{tabular}

Table 3. Memory assessment results during the IAP and EEG results in 16 patients submitted to bilateral injections.

\begin{tabular}{lccccc}
\hline EEG & $\begin{array}{c}\text { Pass-ipsi/ } \\
\text { Fail-contra }\end{array}$ & $\begin{array}{c}\text { Fail } \\
\text { both }\end{array}$ & $\begin{array}{c}\text { Pass } \\
\text { both }\end{array}$ & $\begin{array}{c}\text { Fail-ipsi/ } \\
\text { Pass-contra }\end{array}$ & Total \\
\hline Bitemporal & 7 & 4 & 1 & 1 & 13 \\
Unitemporal & 2 & 1 & 0 & - & 3 \\
Total & 9 & 5 & 1 & 1 & 16 \\
\hline
\end{tabular}

In bitemporal patients, the side associated with MTS on MRI was considered "ipsilateral".

Table 3 shows the results of memory assessment in uni- and bitemporal patients submitted to injections on both cerebral hemispheres. Nine bitemporal patients passed the injection ipsilateral to the MTS (including 2 patients who had only unilateral carotid injections) and 4 failed bilaterally. Seven of these bitemporal patients passed an injection ipsilateral to MTS and failed on contralateral injection. One bitemporal patient passed bilaterally the IAP. Two of the unitemporal lobe patients passed the ipsilateral injection and failed the contralateral one. One of the unitemporal lobe patients failed bilaterally the IAP. Fifty-six percent of the uni- or bitemporal lobe epilepsy patients presented the pass ipsi / fail contralateral pattern on the IAP. As can be seen in Table 4, this pattern could be found in both left and right MTSs. Eight patients (Patients $1,3,4,5,7,8,9,16$ ) were operated (temporal lobe resections), are seizure free and presented no new memory deficit.

\section{COMMENTS}

There is frequently a congruence of data generated by the IAP, EEG, PET and MRI. Interictal hypomctabolism can be seen in $70-80 \%$ of the patients with refractory temporal lobe epilepsy after PET scanning ${ }^{10}$. There is usually a good correlation between this hypometabolism and a failure after the contralateral IAP. Unfortunately, many of the studied populations are not homogeneous and variable results may be obtained.

Only the anterior portion of the hippocampus is inactivated during the IAP when the posterior cerebral artery is not perfused after internal carotid injections. The whole hippocampus would be perfused if the posterior circulation were included in the injection. The anterior portion of the hippocampus is the main target to be removed at surgery. On the other hand, more extensive hippocampal removals are being performed presently and one could raise the question if standard IAPs would be testing the function of the body and tail of the hippocampus. Selective posterior cerebral artery injections have been carried out in some centers. Since it is difficult to monitor the action of the drug and it represents a more risky procedure, it is unlikely that this would become a widespread investigative procedure in epilepsy.

As mentioned before, memory deficits were observed after mesio-temporal structures removals. On the other hand, memory deficits, not as severe as the latter have also been observed after neocortical removals sparing the hippocampal region ${ }^{3}$. This suggested an integrated action of both the neocortex and the hippocampus in memory processing. 
All patients that presented the pass ipsi- / fail contralateral injection pattern on the IAP have unilateral or bilateral epileptiform abnormalities on EEG and MTS in one cerebral hemisphere. Among the patients that failed on memory testing on the side ipsilateral to MTS ( $n=7), 2$ of them presented a peculiar EEG/MTS pattern. One of them had a structural lesion contralateral to MTS (nodular calcification); the other had epileptiform abnormalities restricted to the right cerebral hemisphere, and left MTS. In the group of patients who presented bilateral abnormalities on EEG and unilateral MTS, 11 patients passed after ipsilateral injection and $69 \%$ presented the pass ipsi- $/$ fail contralateral pattern.

Many patients with temporal lobe epilepsy were found to have the pass ipsi- / fail contralateral pattern on the IAP. All the patients who were operated and had this pattern on the IAP are now seizure free and without any additional memory deficit. This pattern might prove to be of lateralizing and prognostic value in such cases.

\section{REFERENCES}

1. Branch C, Milner B, Rasmussen T. Intracarotid sodium amytal for the lateralization of cerebral speech dominance: observations in 123 patients. J Neurosurg 1964, $21: 399-405$.

2. Jones-Gotman $\mathbf{M}$. Commentary: psychological evaluation - testing hippocampal function. In $\mathrm{J}$ Engel $\mathrm{Jr}$ (ed). Surgical treatment of the epilepsies. New York: Raven Press 1987, p 203-211.

3. Jones-Gotman M. Neuropsychological techniques in the identification of epileptic foci. Epilepsy Res 1992, 5(Suppl):87-94.

4. Jones-Gotman M. Presurgical psychological assessment in children: special tests. J Epilepsy 1991, 3(Suppl 1):44-47.

5. Milner B, Branch C, Rasmussen T. Evidence of bilateral speech representation in some non-right-handers. Trans Am Neurol Assoc 1966, 91:306-308.

6. Milner B, Branch C, Rasmussen T. Study of short term memory after intracarotid sodium amytal procedure. Trans Am Neurol Assoc 1962, 87:224-226.

7. Penfield W, Mathieson G. An autopsy and a discussion of the role of the hippocampus in experiential recall. Arch Neurol 1974, 41:145-154.

8. Penfield W, Milner B. Memory deficit produced by bilateral lesions in the hippocampal zone. Arch Neurol Psichiat 1958, 79:475-497.

9. Rasmussen T, Milner B. The role of early left-brain injury in determining lateralization of special speech functions. Ann NY Acad Sci 1977, 299:355-369.

10. Salanova V, Morris HH, Rehm P, Wyllie E, Dinner DS, Luders H, Gilmore-Pollak W. Comparison of the intracarotid amobarbital procedure and interictal cerebral 18-fluorodeoxyglucose positron emission tomography scans in refractory temporal lobe epilepsy. Epilepsia 1992, 33:635-638.

11. Scoville W, Milner B. Loss of recent memory after bilateral hippocampal lesions. J Neurol Neurosurg Psychiatry 1957, 20:11-21.

12. Wada J, Rasmussen T. Intracarotid injection of sodium amytal for the lateralization of cerebral speech dominance: experimental and clinical observations. J Neurosurg 1960, 17:226-282.

13. Zatorre RJ. Perceptual asymmetry on the dichotic fused words test and cerebral speech lateralization determined by the carotid sodium amytal test. Neuropsychologia 1989, 27:1207-1219. 